\title{
Desenvolvimento de algoritmos de inteligência artificial para detecção de defeitos em para-raios a partir de imagens termográficas
}

\section{Development of artificial intelligence} algorithms for detection of defects in surge arresters from thermal images

Samuel Cesarino da Nóbrega1', Pablo Bezerra Vilar², George Rossany Soares de Lira ${ }^{3}$

Cesarino da Nóbrega, S; Bezerra Vilar, P; Soares de Lira, G.R. Desenvolvimento de algoritmos de inteligência artificial para detecção de defeitos em para-raios a partir de imagens termográficas. Tecnología en Marcha. Vol. 34, especial. ALTAE. Diciembre 2021. Pág 220-231.

doi) https://doi.org/10.18845/tm.v34i7.6043

2 Universidade Federal de Campina Grande. Brasil. Correo electrónico: pablo.vilar@dee.ufcg.edu.br 


\title{
Palavras-chave
}

Para-raios; imagens termográficas; backpropagation; redes neurais artificiais; classificação.

\section{Resumo}

Os principais defeitos em para-raios estão comumente associados a elevações de corrente e, por isso, ao aquecimento por efeito Joule. Assim, a termovisão nestes equipamentos é uma técnica adequada para a detecção de defeitos. Porém, tal uso da termovisão depende de um operador experiente para interpretar os resultados obtidos, sujeitando o processo a erros de interpretação. Diante disso, este trabalho tem como objetivo aplicar técnicas de Inteligência Artificial na classificação de imagens térmicas de para-raios como forma de tornar o processo mais confiável. Foram desenvolvidos algoritmos de inteligência artificial baseados em técnicas de Redes Neurais Artificiais e deep learning, tendo em vista que muitos autores obtiveram sucesso na utilização destes métodos no diagnóstico de falhas em outros equipamentos do sistema elétrico de potência. Os resultados obtidos mostraram que as redes neurais desenvolvidas pelo método backpropagation apresentaram uma boa eficiência ao classificar imagens de para-raios e que não há necessidade de segmentar o para-raios da imagem termográfica para realizar a classificação.

\section{Keywords}

Surge arresters; thermal images; backpropagation; artificial neural networks; classification.

\begin{abstract}
The main faults in surge arresters are commonly associated with current rises and, therefore, with heating by the Joule effect. Thus, thermovision is a very suitable technique for detecting defects in this electrical power system equipment. However, the use of thermovision to identify possible failures in surge arresters depends on an experienced operator to interpret the obtained results, which many times are subject to interpretation errors. This work aims to apply Artificial Intelligence techniques to classify surge arrester thermal images. Artificial Intelligence algorithms based on Artificial Neural Networks and deep learning techniques were developed for this purpose, considering that many authors have succeeded in using these methods in failure diagnosis in other equipment in the electrical power system. The results obtained showed that the neural networks developed by the backpropagation algorithm presented good efficiency when classifying surge arrester thermal images, and there is no need to segment the surge arrester from the thermal image to carry out the classification.
\end{abstract}

\section{Introdução}

Os para-raios de óxido de zinco $(\mathrm{ZnO})$ são equipamentos largamente utilizados em sistemas elétricos com o intuito de proteger os demais equipamentos contra surtos atmosféricos e de manobra e auxiliando na coordenação de isolamento de subestações elétricas. Atuam de forma a limitar o nível de tensão que atinge os equipamentos do sistema, como os transformadores, evitando que os mesmos sejam atingidos por uma sobretensão superior a sua suportabilidade [1]. Dessa forma, os para-raios são elementos fundamentais para a confiabilidade, economia e continuidade de operação dos sistemas elétricos de potência [2].

Devido à importância dos para-raios, torna-se necessário o desenvolvimento e aprimoramento de técnicas e procedimentos para a identificação de possíveis falhas e defeitos, uma vez que sua falha pode causar danos aos demais equipamentos do sistema, bem como ocasionar 
desligamentos não programados e, consequentemente, possíveis transtornos e prejuízos, tais como paralisação de produções industriais, hospitalares ou até mesmo das atividades comerciais e residenciais.

Defeitos em para-raios estão comumente associados a elevações de corrente e consequente aquecimento, de modo que a observação de um padrão de aquecimento no equipamento pode ser utilizada como elemento de detecção de defeitos [3]. Por isso, o uso de termovisão surge como uma possível técnica de inspeção para detecção de defeitos em para-raios.

A termografia é uma técnica não invasiva que permite o monitoramento do para-raios e mapear as áreas de diferentes temperaturas. As principais vantagens do uso da termografia em comparação com os demais métodos de inspeção dizem respeito à ausência de contato físico com o para-raios, a não necessidade de retirá-los de operação e a exibição dos resultados em um curto intervalo de tempo. No entanto, a termografia apresenta como desvantagem a dependência de um operador experiente para interpretar os resultados obtidos, que, muitas vezes, estão sujeitos a erros de interpretação.

Nesse contexto, vários pesquisadores propuseram a utilização de técnicas de Inteligência Artificial (IA) na identificação de defeitos em para-raios, a exemplo de [4-6], o que seria uma possível forma de aprimorar a detecção de defeitos em para-raios por meio de imagens termográficas. Além disso, vários autores obtiveram sucesso ao desenvolver classificadores inteligentes na análise de imagens termográficas de equipamentos do sistema elétrico de potência, dentre os quais vale destacar os que são baseados nas técnicas deep learning [7-10], SVM [11-13] e Redes Neurais Artificiais (RNA) baseadas no algoritmo backpropagation [14-17]. Diante disso, este trabalho tem como objetivo implementar técnicas de IA e aplicá-las na identificação de defeitos em para-raios a partir de imagens termográficas. Para tanto, foram desenvolvidos algoritmos de IA baseados em técnicas de RNA, por meio de um software de programação interativo voltado para cálculo numérico.

\section{Fundamentação teórica}

As Redes Neurais Artificiais (RNA) são um tipo de IA capaz de realizar aprendizagem e o reconhecimento de padrões. A estrutura de uma RNA é inspirada no sistema nervoso biológico do próprio cérebro humano em dois aspectos [18]: o conhecimento é adquirido pelo ambiente, por meio do processo de aprendizagem, e são utilizadas forças de conexão entre neurônios, conhecidos como pesos sinápticos, para o armazenamento do conhecimento e reconhecimento de padrões.

As RNA's são dotadas de unidades processadoras, denominadas de neurônios artificiais, que são modelos matemáticos inspirados nos neurônios biológicos. O funcionamento dos neurônios artificiais consiste em receber sinais de entrada e multiplicar pelos seus respectivos pesos sinápticos. Os resultados obtidos serão a soma ponderada de suas entradas, por meio de uma combinação linear entre os pesos e a entrada.

O modelo básico de RNA possui diferentes componentes, dentre os quais: [19] o conjunto de sinapses, o somador, a função de ativação e o bias. O conjunto de sinapses corresponde às conexões entre os neurônios da RNA, as quais possuem pesos sinápticos. O somador diz respeito às somas dos sinais propagados ao longo da RNA, ponderados pelos pesos sinápticos. A função de ativação é responsável pela redução dos valores dos neurônios das camadas ocultas e da camada de saída. Existem diversas funções de ativação, das quais as mais populares são as funções limiar, tangente hiperbólica, sigmóide e ReLu. O bias é um 
valor que cada neurônio possui, o qual será somado aos valores obtidos pelo integrador para o cálculo da função de ativação. Na figura 1 se encontra um modelo de processamento de um neurônio artificial.

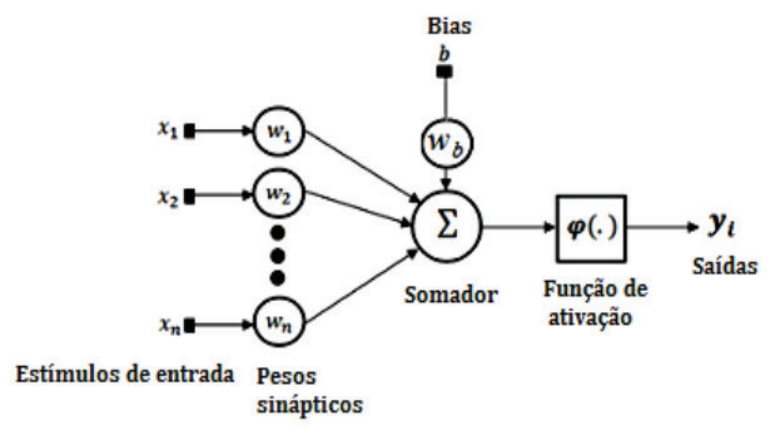

Figura 1. Modelo de um neurônio artificial. Fonte: [18].

A forma mais simples de representar uma configuração de uma RNA é pelo modelo de rede perceptron, o qual consiste em um único neurônio e uma única camada oculta, conforme representado na figura 2.

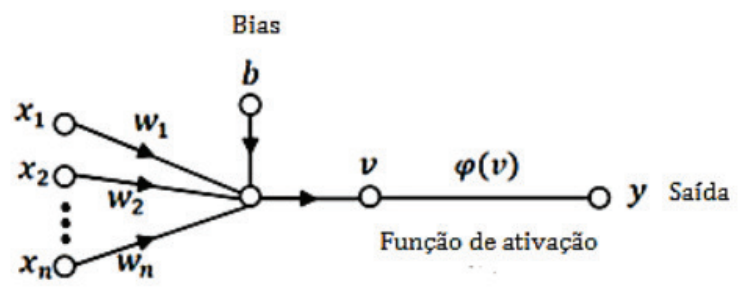

Figura 2. Modelo de uma rede perceptron. Fonte: Adaptado de [18] por [17].

Uma RNA é dividida em três grupos de camadas: a camada de entrada, onde os valores de entrada são apresentados à rede, as camadas ocultas, que correspondem aos neurônios artificiais, e a camada de saída, onde o resultado final é apresentado. As entradas são propagadas por meio das conexões entre os neurônios artificiais. Em seguida, passa por transformações pelos pesos sinápticos e pela função de ativação dos neurônios. Por fim, o resultado final é concluído e apresentado na camada de saída.

O estudo da inteligência artificial tem várias vertentes. Para o contexto deste trabalho, destacase o deep learning, que é caracterizado por um aprendizado hierárquico dos dados de entrada, aprendendo inicialmente atributos simples de baixo nível que serão utilizados para construir sucessivamente representações mais complexas. Um exemplo de aprendizado hierárquico está ilustrado na figura 3, no qual a camada de entrada recebe uma imagem para reconhecimento facial, enquanto as camadas ocultas aprendem a representar características de baixo nível, como os contornos e formatos de rosto, bem como características de alto nível, como os olhos e o comprimento do cabelo. 


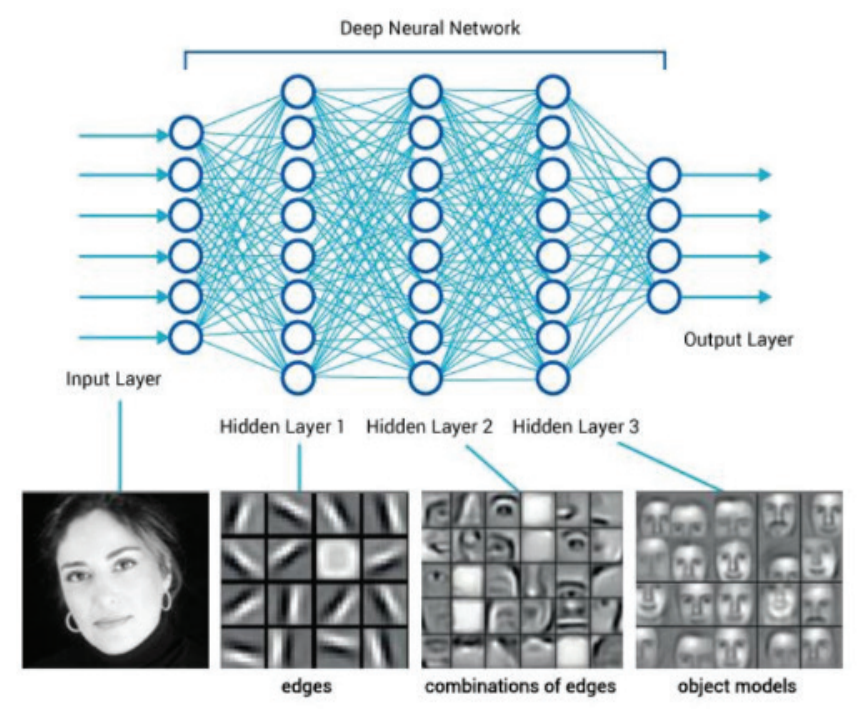

Figura 3. Classificador utilizado para reconhecimento facial. Fonte: [20].

A representação mais simples de deep learning é por meio da multilayer perceptron (MLP) [21], também conhecida como Deep Neural Network (DNN). A arquitetura de uma rede multilayer perceptron consiste em uma RNA semelhante à perceptron, porém com múltiplas camadas de neurônios em alimentação direta, conforme indicado na figura 4. Uma DNN consiste em uma MLP com mais de uma camada oculta de neurônios.

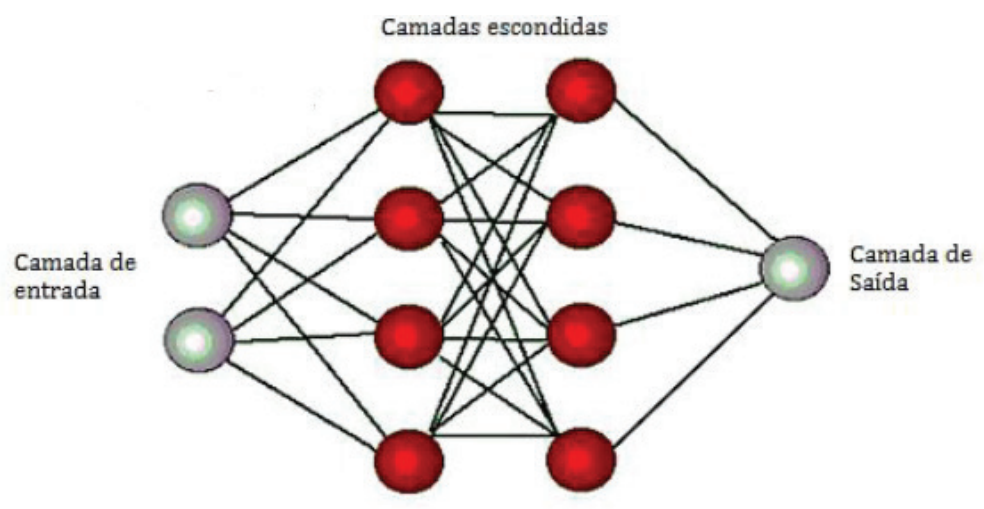

Figura 4. Estrutura de uma RNA. Fonte: [22].

Durante o processo de aprendizagem, a RNA passa primeiramente pelo processo de treinamento, no qual a mesma recebe dados de treinamento e, por meio de processos iterativos, define os pesos sinápticos. Em seguida, a RNA é submetida a um teste, por meio de um banco de dados teste, a fim de averiguar o funcionamento da mesma. Por fim, o desempenho das redes neurais foi avaliado. Algumas das formas de avaliar o desempenho de uma RNA são pelas acurácias de treinamento e de teste. A acurácia de treinamento é dada pela razão entre o número de dados de treinamento classificados corretamente e a quantidade de dados de treinamento, quando o banco de dados teste é o próprio banco de treinamento. Já a acurácia de teste corresponde à mesma razão, porém com o banco de dados de teste sendo o próprio banco destinado com esta finalidade. 
O algoritmo de treinamento mais utilizado é o backpropagation, que é baseado na retropropagação dos erros para realizar os ajustes dos pesos das camadas ocultas. A aprendizagem da rede neural por este algoritmo ocorre quando é encontrada uma solução geral para um conjunto de problemas e seu desempenho é otimizado por meio do processo iterativo de ajuste de pesos durante a etapa de treinamento.

\section{Metodologia}

Para caracterização do comportamento dos para-raios, foram utilizados os resultados experimentais oriundos do trabalho de [4]. A base de dados disponível neste trabalho é formada por imagens térmicas realizadas durante ensaios de operação em amostras de pararaios íntegros e com defeitos criados artificialmente. Os defeitos inseridos nos para-raios foram: perda de estanqueidade, entrada de umidade, poluição superficial, degradação dos varistores, desalinhamento da coluna ativa e distribuição irregular de tensão.

Ao todo, a base de dados é composta por 464 imagens térmicas de duas amostras de pararaios da classe de $96 \mathrm{kV}$, das quais 80 termografias eram de ambos os para-raios em estado íntegro e as demais dos para-raios com os defeitos inseridos.

O conjunto de dados foi utilizado como insumo para o desenvolvimento de classificadores inteligentes que tinham por objetivo diferenciar as imagens térmicas de para-raios íntegros e para-raios defeituosos. A programação dos classificadores foi realizada por meio do software GNU Octave, o qual é gratuito e possui linguagem de programação de alto nível, direcionada para cálculo numérico. Ele dispõe de uma interface de linha de comando conveniente para solução de problemas numéricos lineares e não lineares, permitindo um aprendizado rápido e desenvolvimento simplificado de algoritmos de inteligência artificial.

Assim, foram aplicadas técnicas de classificação inteligente com estrutura de RNA e deep learning. Inicialmente, foram desenvolvidas RNA's de apenas uma camada oculta e diferentes quantidades de neurônios artificiais, baseadas no algoritmo backpropagation. Foram desenvolvidas duas estruturas de redes neurais: Estrutura 1 e Estrutura 2, conforme ilustrado nas Figuras 5 e 6, respectivamente.

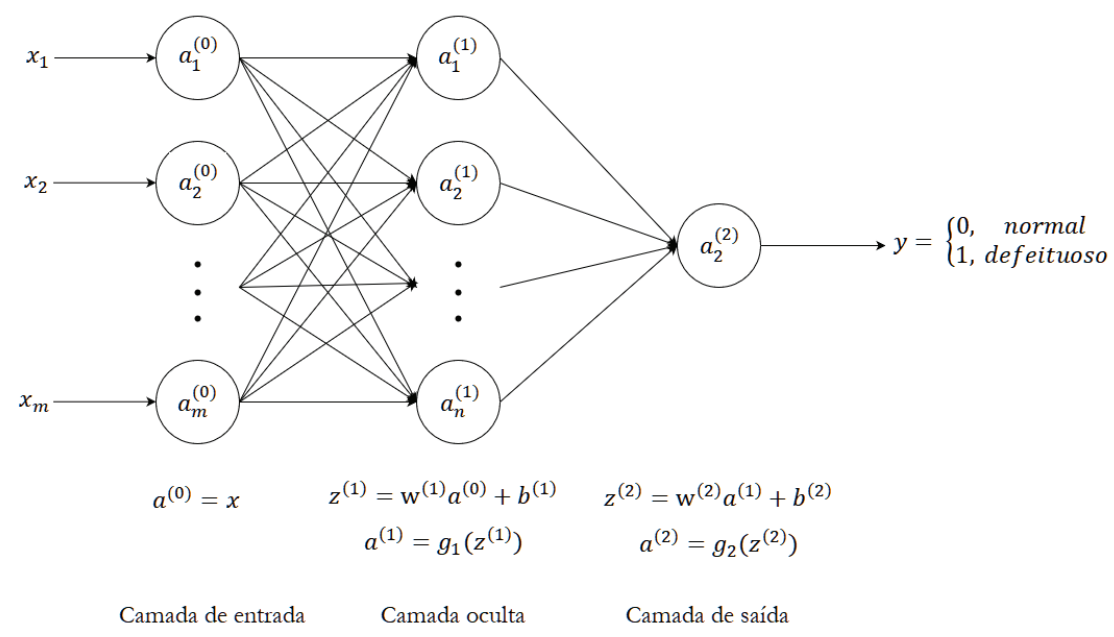

Figura 5. Estrutura 1. 


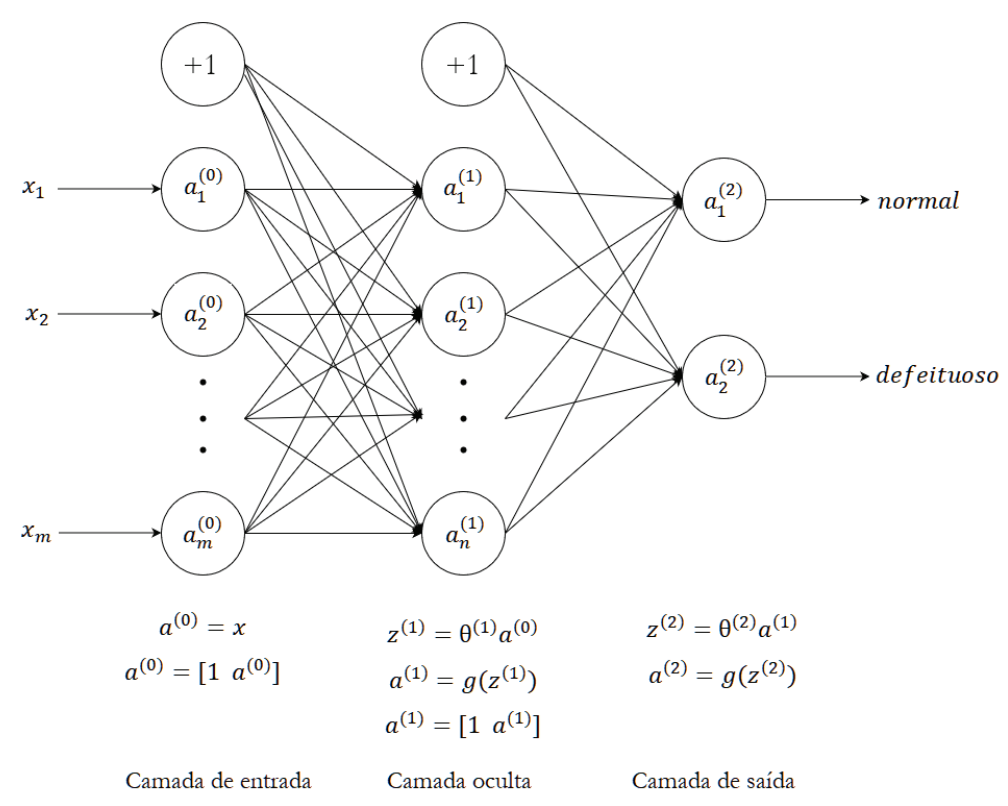

Figura 6. Estrutura 2.

A Estrutura 1 possui três camadas. A camada de entrada recebe os pixels das imagens termográficas dos para-raios e possui m neurônios artificiais, que correspondem aos pixels das imagens. Os coeficientes $a^{(0)}$ são dados pela razão entre o valor do pixel recebido e 255 , que é o valor máximo que o pixel pode atingir. A camada oculta possui n neurônios artificiais, cujos valores foram variados, a fim de avaliar o desempenho do sistema em função de n. Os coeficientes $a^{(1)}$ são obtidos pelas seguintes equações:

$$
\begin{aligned}
& \boldsymbol{z}^{(1)}=\boldsymbol{w}^{(1)} \boldsymbol{a}^{(0)}+\boldsymbol{b}^{(1)} \\
& \boldsymbol{a}^{(1)}=g_{1}\left(\mathbf{z}^{(1)}\right) \\
& g_{1}(z)=\left\{\begin{array}{l}
z, z \geq 0 \\
0, z<0
\end{array}\right.
\end{aligned}
$$

onde $z^{(1)}$ é o vetor pesos de entrada da função de ativação $g_{1}(z), w^{(1)}$ é o vetor de pesos da conexão entre a camada de entrada e a camada oculta, $b^{(1)}$ é o vetor bias dos neurônios da camada oculta e $g_{1}(z)$ é a função de ativação, que, para a camada oculta, é a função ReLu, dada por (3). Por fim, a camada de saída possui apenas um neurônio, que receberá peso 0 se o para-raios for classificado como íntegro ou peso 1 se o para-raios for classificado como defeituoso. Os coeficientes $a^{(2)}$ são calculados pelas seguintes equações:

$$
\begin{aligned}
& \boldsymbol{z}^{(2)}=\boldsymbol{w}^{(2)} \boldsymbol{a}^{(1)}+\boldsymbol{b}^{(2)} \\
& \boldsymbol{a}^{(2)}=g_{2}\left(\mathbf{z}^{(2)}\right)
\end{aligned}
$$




$$
g_{2}(z)=\frac{1}{1+e^{-z}}
$$

onde $z^{(2)}$ é o vetor pesos de entrada da função de ativação $g_{2}(z), w^{(2)}$ é o vetor de pesos da conexão entre a camada oculta e a camada de saída, $b^{(2)}$ é o vetor bias da camada de saída e $g_{2}(z)$ é a função de ativação, que, para a camada de saída, é a função sigmóide, dada por (6).

A Estrutura 2 é semelhante à Estrutura 1, porém com algumas diferenças, tais como: a adição de um neurônio de peso unitário para o cálculo dos coeficientes $a^{(1)}$ e $a^{(2)}$, a função de ativação da camada oculta, que nessa Estrutura é a sigmóide, a ausência dos parâmetros $b^{(1)}$ e $b^{(2)}$ no cálculo de $z^{(1)}$ e $z^{(2)}$ e a existência de um segundo neurônio na camada de saída.

Em seguida, foi desenvolvida uma rede DNN, com duas camadas ocultas, a fim de comparar o desempenho com as redes neurais simples de apenas uma camada. O treinamento foi realizado a partir do banco de imagens de treinamento e o desempenho das redes de cada técnica foi avaliado a partir do banco de imagens de teste. Foram utilizadas 40 imagens de para-raios íntegros e 288 imagens de para-raios defeituosos para o treinamento e as demais foram destinadas ao teste de avaliação do desempenho do sistema desenvolvido.

Por fim, foram realizadas segmentações nas imagens termográficas, extraindo apenas o pararaios das mesmas, de forma a eliminar as informações inúteis e comparar o desempenho das redes neurais ao classificar imagens segmentadas e imagens não-segmentadas.

\section{Resultados}

Para as redes neurais da Estrutura 1, foram realizadas 50 mil iterações para a obtenção dos resultados, enquanto para as redes da Estrutura 2 foram realizadas 10 mil iterações. Os gráficos de barras que contém os resultados obtidos para as redes da Estrutura 1 para a classificação de imagens termográficas não-segmentadas se encontram na figura 7.

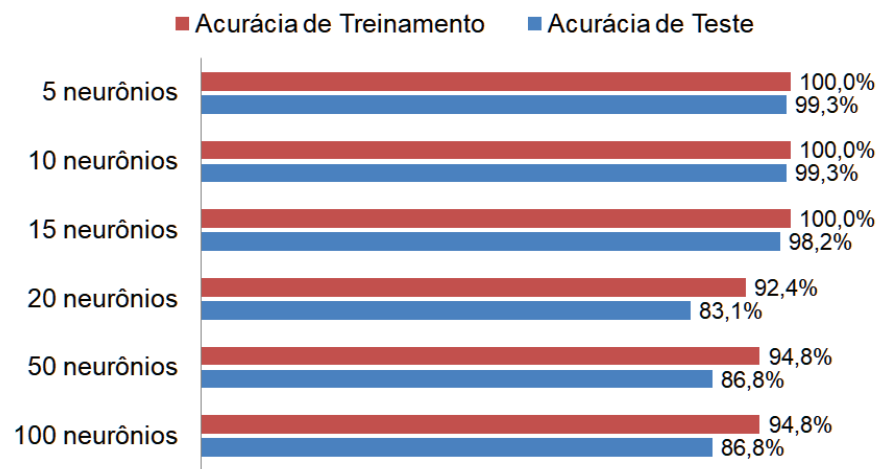

Figura 7. Desempenho das redes neurais da Estrutura 1 na classificação de imagens termográficas não-segmentadas.

Conforme ilustrado na figura 7, as RNA's de Estrutura 1 apresentaram resultados satisfatórios, uma vez que as acurácias de treinamento são superiores a 90\% e a divergência entre as acurácias de treinamento e de teste não são significativas. Os melhores resultados ocorreram para uma quantidade de neurônios artificiais inferior a 20, os quais apresentaram acurácia de treinamento igual a 100\% e acurácia de teste superior a 98\%. 
Para as redes com quantidades de neurônios artificiais iguais ou superiores a 20, as acurácias de treinamento foram inferiores a $100 \%$ e as acurácias de teste foram inferiores a 90\%. Com o intuito de melhorar o desempenho dos sistemas desenvolvidos, foram desenvolvidas redes DNN de duas camadas ocultas e com diferentes quantidade de neurônios, com estrutura semelhante à Estrutura 1. Os resultados obtidos para a inserção da nova camada oculta se encontram na figura 8.

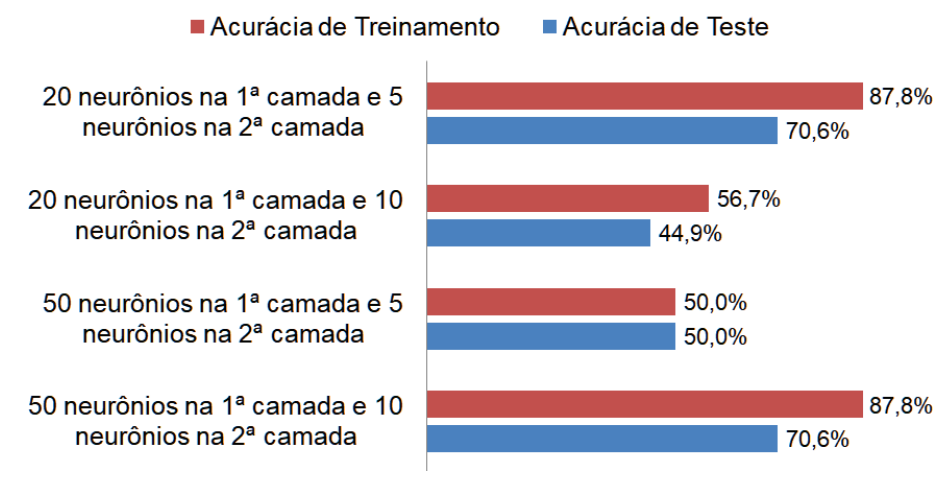

Figura 8. Desempenho das redes DNN de duas camadas ocultas na classificação de imagens termográficas não-segmentadas.

Conforme apresentado na figura 8, o acréscimo de uma nova camada oculta não melhorou 0 desempenho das redes neurais desenvolvidas. As acurácias de treinamento foram inferiores a 90\% e as acurácias de teste foram inferiores a $75 \%$.

Em seguida, realizaram-se segmentações nas imagens termográficas, de forma a eliminar as informações inúteis e deixar apenas o para-raios presente nas imagens, a fim de avaliar o desempenho das redes neurais de Estrutura 1 quando as imagens são segmentadas e comparar com os casos em que as imagens não são segmentadas. Os gráficos comparativos de ambos os casos se encontram na figura 9.

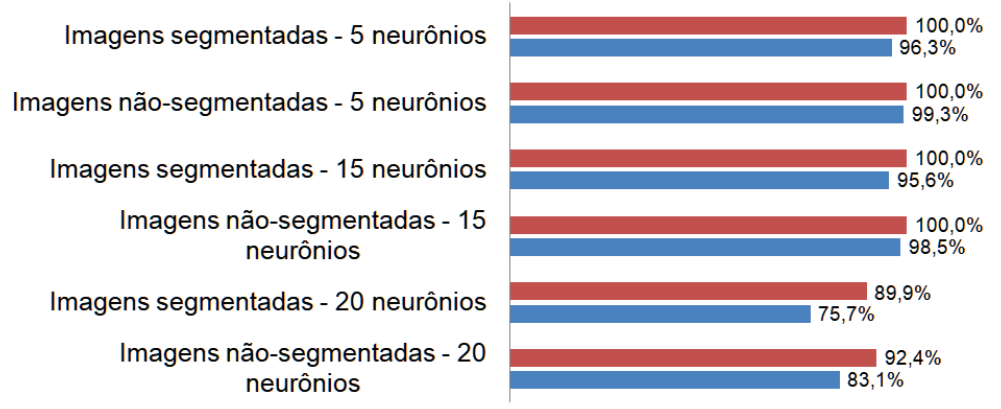

Figura 9. Comparação entre os desempenhos das RNA's de Estrutura 1 na classificação de imagens não-segmentadas e de imagens segmentadas.

Ao comparar os resultados obtidos ao segmentar o para-raios da imagem termográfica com os resultados obtidos quando os para-raios não eram segmentados, nota-se que a segmentação não melhora o desempenho das redes neurais ao classificar o estado do para-raios a partir de imagens termográficas, uma vez que as acurácias para as imagens segmentadas são iguais ou inferiores às acurácias para as imagens não-segmentadas. Dessa forma, para os classificadores 
desenvolvidos, não há necessidade de segmentar o para-raios da imagem termográfica para realização da classificação. Destaca-se que, esse comportamento é inesperado e deve ser melhor avaliado utilizando uma base de dados mais ampla em trabalhos futuros.

Dando continuidade, foram desenvolvidos sistemas de classificação a partir de redes neurais de Estrutura 2. Os gráficos com os resultados obtidos na classificação de imagens sem segmentação do para-raios se encontram na figura 10.

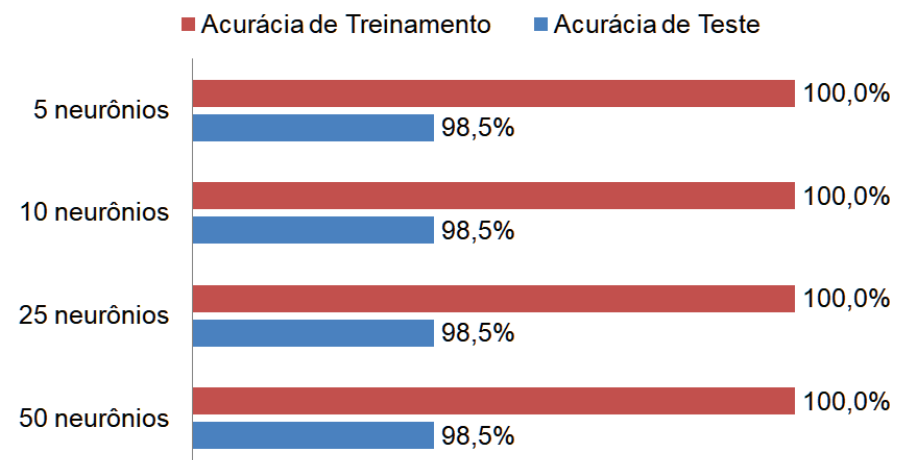

Figura 10. Desempenho das redes neurais da Estrutura 2 na classificação de imagens termográficas não-segmentadas.

Conforme mostrado na Figura 10, todas as redes neurais desenvolvidas apresentaram a mesma acurácia de treinamento e de teste, mostrando que o número de neurônios claramente não tem impacto sobre o desempenho do classificador. Além disso, os resultados obtidos para esta estrutura foram satisfatórios, uma vez que apresenta uma alta taxa de acerto e baixa divergência entre as acurácias de treinamento e de teste.

Por fim, da mesma forma como foi feito na Estrutura 1, realizou-se o treinamento das redes de Estrutura 2 para classificação das imagens com segmentação dos para-raios, a fim de verificar o desempenho do sistema em comparação com as imagens não-segmentadas. Os gráficos com os resultados se encontram na figura 11.

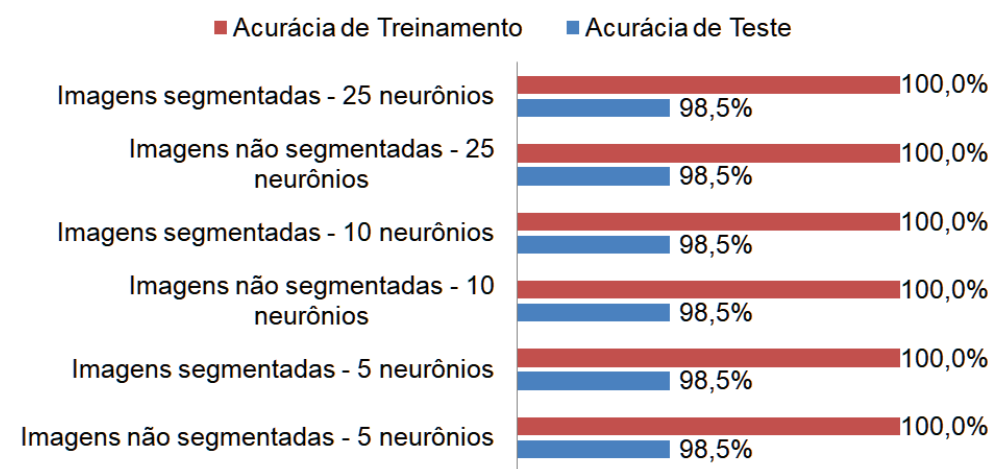

Figura 11. Comparação entre os desempenhos das RNA's de Estrutura 2 na classificação de imagens não-segmentadas e de imagens segmentadas. 
Conforme apresentado na figura 11, os sistemas apresentaram o mesmo desempenho para as imagens com segmentação dos para-raios, apresentando os mesmos valores de acurácias de treinamento e de teste. Dessa forma, para as RNA's de camada única oculta baseadas no algoritmo backpropagation, a segmentação do para-raios das imagens não tem influência no desempenho do sistema de classificação.

\section{Conclusão}

Neste trabalho, foram desenvolvidas redes neurais artificiais com o intuito de classificar o estado de para-raios a partir de imagens termográficas e aprimorar o uso da termovisão na detecção de defeitos neste tipo de equipamento. Para isso, o software de programação GNU Octave ${ }^{\circledR}$ foi utilizado para a programação dos classificadores.

Os resultados obtidos mostraram que as RNA's baseadas no algoritmo backpropagation realmente são eficientes ao classificar imagens termográficas, comprovando o sucesso desta técnica de IA em trabalhos anteriores. Os melhores classificadores de imagens termográficas de para-raios possuíam apenas uma única camada oculta e quantidade de neurônios artificiais inferior a 20. Além disso, foi possível constatar que não houve necessidade de segmentar o para-raios da imagem termográfica para realizar a classificação.

Os resultados deste trabalho poderão ser úteis para diminuir a incidência de erros de classificação do estado de para-raios, bem como na diminuição da dependência de um operador experiente para a interpretação dos resultados das medições termográficas. Em trabalhos futuros, pretende-se expandir a base de dados utilizada para aumentar a confiabilidade do sistema e validar os resultados obtidos. Além disso, pretende-se utilizar esse mesmo sistema para identificar defeitos em outros equipamentos do sistema, bem como melhorar o sistema desenvolvido para que seja possível classificar o tipo de defeito nos para-raios.

\section{Referências}

[1] A. D’Ajuz, F. M. Resende, F. M. S. Carvalho, I. G. Nunes, J. Amon Filho, L. E. N. Dias, M. P. Pereira, O. Kastrup Filho, S. A. Morais, "Equipamentos Elétricos: Especificação e Aplicação em Subestações de Alta Tensão", Universidade Federal Fluminense, Brasil, 1985.

[2] V. Hinrichsen, "Metal-Oxide Surge Arresters Fundamentals", Siemens AG, 1st edition, 2001.

[3] C. Heinrich \& V. Hinrichsen, "Diagnostics and monitoring of metal-oxide surge arresters in high-voltage networks-comparison of existing and newly developed procedures", In IEEE Transactions on Power Delivery, vol. 16, no. 1, pp. 138-143, Jan. 2001. https://doi.org/10.1109/61.905619.

[4] G. R. S. Lira, "Monitoramento de Para-raios de Óxido de Zinco com Base na Medição da Corrente de Fuga Total", Tese de Doutorado, Universidade Federal de Campina Grande, Brasil, 2012.

[5] E. T. Wanderley Neto, "Monitoramento e Diagnóstico de Para-raios a ZnO Através de Redes Neurais Artificiais", Tese de Doutorado, Universidade Federal de Campina Grande, Brasil, 2007.

[6] G. R. S. Lira, E. G. da Costa, D. Fernandes Júnior, V. D. S. Brito, M. J. A. Maia, "Sistema Automático de Diagnóstico de Falhas em Para-raios de ZnO Baseado na Análise de Termografias", XXI Seminário Nacional de Produção e Transmissão de Energia Elétrica (SNPTEE), Florianópolis, Brasil, Outubro, 23 - 26, 2011.

[7] G. Mazoni, "Sistema para Interface e Diagnóstico de Inspeções Termográficas Automatizadas por Inteligência Artificial para Redes de Distribuição de Energia Elétrica”, Tese de Doutorado, Universidade Estadual de Campinas, Brasil, 2018.

[8] Y. Higuchi \& T. Babasaki, "Failure detection of solar panels using thermographic images captured by drone", 2018 7th International Conference on Renewable Energy Research and Application (ICRERA), 2018, pp. 391396. https://doi.org/10.1109/ICRERA.2018.8566833

[9] H. P. C. Hwang, C. C. Y. Ku \& J. C. C. Chan, "Detection of Malfunctioning Photovoltaic Modules Based on Machine Learning Algorithms", In IEEE Access, vol. 9, pp. 37210-37219, 2021 https://doi.org/10.1109/ ACCESS.2021.3063461 
[10] X. Gong, Q. Yao, M. Wang \& Y. Lin, "A Deep Learning Approach for Oriented Electrical Equipment Detection in Thermal Images", In IEEE Access, vol. 6, pp. 41590-41597, 2018, https://doi.org/10.1109/ ACCESS.2018.2859048

[11] J. Chen, Y. Li \& Q. Ling, "Hot-Spot Detection for Thermographic Images of Solar Panels", 2020 Chinese Control And Decision Conference (CCDC), pp. 4651-4655, https://doi.org/10.1109/CCDC49329.2020.9164255

[12] Y. Olivatti, C. Penteado, P. T. Aquino \& R. F. Maia, "Analysis of artificial intelligence techniques applied to thermographic inspection for automatic detection of electrical problems", 2018 IEEE International Smart Cities Conference (ISC2), pp. 1-5, https://doi.org/10.1109/ISC2.2018.8656724

[13] H. Zou, \& H. Fuzhen, "An Intelligent Fault Diagnosis Method for Electrical Equipment Using Infrared Images", Proceedings of the 34th Chinese Control Conference, pp. 6372-6376, 2015. https://doi.org/10.1109/ChiCC.2015.7260642

[14] S. A. Merryman \& R. M. Nelms, "Diagnostic technique for power systems utilizing infrared thermal imaging", In IEEE Transactions on Industrial Electronics, vol. 42, no. 6, pp. 615-628, Dec. 1995, https://doi. org/10.1109/41.475502

[15] G. M. Santos, "Termografia e Inteligência Artificial na Detecção de Falhas em Transformadores", Tese de doutorado, Universidade Federal do Pernambuco, Brasil, 2017.

[16] R. H. F. Alves, G. A. Deus Júnior, F. H. T. Vieira, M. S. Castro, S. G. Araújo, R. P. Lemos, "Detecção de Anomalias em Painéis Fotovoltaicos Utilizando Redes ABNET, PSOM e MLP", VI Congresso Brasileiro de Energia Solar (CBENS), Belo Horizonte, Brasil, Abril, 04 - 07, 2016.

[17] G. L. Ribeiro, "Aprimoramento da Classificação de Isoladores Poliméricos por Medições Termográficas e Radiação UV”, Tese de doutorado, Universidade Federal de Campina Grande, Brasil, 2017.

[18] S. Haykin, "Redes Neurais - Princípios e Práticas", Bookman, 2001.

[19] A. P. Braga, T. B. Ludermir, A. C. P. L. F. Carvalho, "Redes Neurais Artificiais: Teoria e Aplicações", Rio de Janeiro: LTC, 2000.

[20] N. Yali, "A Multi-stage Convolution Machine with Scaling and Dilation for Human Pose Estimation", Thesis (Master degree Department of Electronic Engineering), Graduate School of Chonbuk National University, Republic of Korea, 2018.

[21] I. Goodfellow, Y. Bengio, \& A. Courville, "Deep Learning", Cambridge, MA: MIT Press, 2016

[22] L. S. Abdalla \& C. F. S. Volotão, "Estudo da Configuração de Diferentes Arquiteturas de Redes Neurais Artificiais MLP para Classificação de Imagens Ópticas", XVI Simpósio Brasileiro de Sensoriamento Remoto (SBSR), Foz do Iguaçu, Brasil. INPE, 2013. 